\section{LOGISTICA DA DISTRIBUIÇÃo BANCÁRIA: TENDÊNCIAS, OPORTUNIDADES E FATORES PARA INCLUSÃO FINANCEIRA}

Marcos Bader 4025.bader@bradesco.com.br

Diretor-geral do Bradesco Cartões - São Paulo - SP, Brasil

José Roberto Ferreira Savoia jrsavoia@usp.br

Professor da Faculdade de Economia, Administração e Contabilidade, Universidade de São Paulo - São Paulo, SP, Brasil

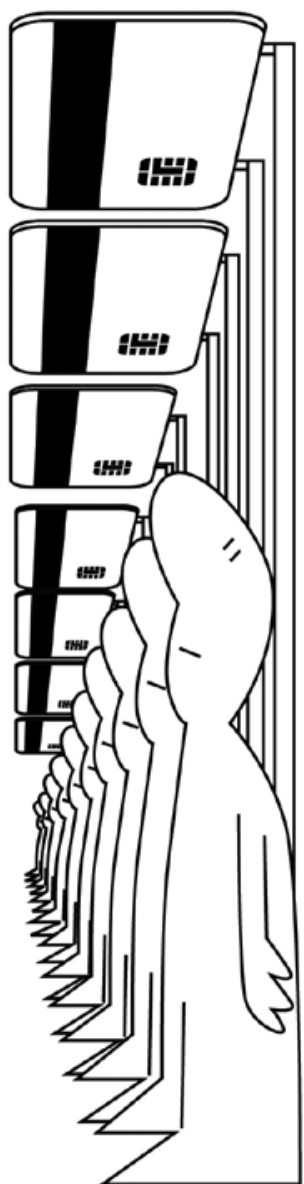

volve tecnologias de prestação de serviços bastante alinhadas com as especificidades do País (Fonseca, MEIRELLES, DINIZ, 2010). Com cerca de $90 \%$ das transações financeiras realizadas em canais eletrônicos, os bancos de grande porte, no Brasil, já se posicionam para reconfigurar a logística bancária na direção da convergência e da mobilidade.

A logística bancária, em especial aquela baseada nos canais eletrônicos de atendimento, cumpre papel fundamental na oferta dos produtos e serviços aos consumidores. A diversificação dos canais bancários promove uma constante dinamização da prestação dos serviços financeiros e cria um novo 
cenário concorrencial no setor, em que agentes financeiros e não financeiros atuam em conjunto, alterando o paradigma tradicional de distribuição e prestação de serviços, que passa a se orientar para a virtualização e a inclusão financeira.

Cernev, Diniz e Jayo (2009) apontam essa mudança no paradigma na distribuição de serviços financeiros por meio de uma quinta onda de inovação em tecnologia bancária, influenciada pelo ambiente de mobilidade e convergência digital. Essa quinta onda manifesta-se na diversificação dos canais bancários, com foco especial no uso de celulares e de correspondentes bancários, com a finalidade de expandir a atuação dos bancos para além dos seus limites tradicionais, ampliando o mercado e atingindo o público de mais baixa renda.

Essa nova logística bancária permite maior capilaridade, menores custos e é orientada às necessidades dos clientes, favorecendo a inclusão no sistema bancário e a universalização do acesso aos serviços financeiros. Como as necessidades desse público de baixa renda diferem daquelas do público atualmente atendido pelos bancos, os modelos de negócio bancário devem ser adequados ao universo da inclusão financeira.

Este ensaio analisa os fatores mercadológicos, regulatórios, comportamentais e tecnológicos para a inclusão financeira nesse novo cenário e para a logística bancária, com base na observação de práticas do setor no Brasil. Para tanto, pretende-se, também, avaliar aqui as expectativas e necessidades dos clientes de baixa renda e o surgimento dos novos modelos de negócio na prestação de serviços financeiros no novo contexto.

\section{NOVO PARADIGMA DA LOGÍSTICA BANCÁRIA}

A otimização dos canais físicos e eletrônicos que compõem o arsenal de distribuição bancária permite viabilizar economicamente o acesso a um percentual cada vez maior da população, representando uma ferramenta de política econômica e social de grande alcance e efetividade. Especificamente, os canais virtuais ou eletrônicos adicionam um poderoso elemento a essa logística bancária, ocupando espaço e relevância cada vez maiores no setor financeiro, produzindo mudanças e gerando oportunidades para a transformação da logística bancária ao redor do mundo.

$\mathrm{Na}$ medida em que as transações migram para o ambiente eletrônico, a demanda pelos canais físicos diminui. Atualmente, o volume transacionado por cartões representa, mundialmente, em torno de $20 \%$ do valor transacionado no consumo privado, fato que indica o enorme potencial de substituição da moeda física pela eletrônica, corroborando a possível reformulação do modelo vigente.

Novas tecnologias vêm permitindo a oferta e disseminação de serviços e produtos bancários em configurações que outrora não seriam possíveis, barateando significativamente os custos dos canais de distribuição e revisitando processos já existentes. Isso leva a uma alteração na logística bancária, que passa a contar com novos canais e com o aumento da quantidade de potenciais clientes, viabilizando a inclusão financeira.
O uso dos meios virtuais de comunicação também alterou o relacionamento entre bancos e clientes, viabilizando um canal de comunicação bidirecional muito mais eficiente para segmentação, tornando possível um direcionamento mais assertivo de produtos e serviços aos clientes que, de fato, se interessariam.

Essa realidade pode ser interpretada com base em dois cenários: no primeiro deles, os bancos sofrem pressão de instituições não financeiras que ingressam no mercado de meios de pagamentos e financiamentos, cortando margens e conformando-se com um processo de desintermediação financeira; no segundo, em sentido oposto, o avanço de modelos de negócios e as novas tecnologias permitem que as instituições financeiras aumentem a gama de serviços prestados, utilizando-se do conhecimento adquirido sobre seus clientes e investindo no surgimento de novos mercados.

Reforçando o primeiro cenário, temos como exemplo as empresas de telecomunicações, fazendo uso de sua infraestrutura de rede para oferecer alternativas de pagamento eletrônico. Outro exemplo são as empresas de consumo - tais como supermercados - que estruturam suas próprias financeiras ou estabelecem acordos com instituições dessa área, propondo uma revisão da função e dos modelos de negócio dos intermediadores financeiros. Há, ainda, empresas que, como o PayPal, incorporam um elo adicional à cadeia de meios de pagamento, também ocupando o espaço tradicionalmente reservado a empresas do setor bancário. Nesse cenário, o risco para os bancos é ver seus serviços regulares transformados 
em commodity, pressionando suas margens e reforçando a desintermediação financeira.

Para confirmar o segundo cenário, os bancos deveriam aprofundar o relacionamento com clientes, aumentando sua percepção do custo de troca para outro prestador dos mesmos serviços (THE ECONOMIST, 2012, p. 14). Esse cenário oferece uma nova oportunidade às instituições financeiras de fazer uso de sua reputação e conhecimento dos serviços no mercado virtual, atuando de maneira cooperada com empresas de outros segmentos. Um exemplo seria o desenvolvimento em parceria com a indústria de telecomunicações de soluções que ofereçam aplicativos baseados em geolocalização.

Para os bancos, as novas oportunidades que decorrem dessa evolução tecnológica dependem do desenvolvimento desses cenários e de uma revisita aos modelos de negócio e à cadeia de valor do setor financeiro. $\mathrm{Na}$ perspectiva dos bancos, esse paradigma logístico emergente demanda, por um lado, um grande esforço para se manter relevante na cadeia de valor, e, por outro, a necessidade de aproximar-se do cliente final, buscando, dessa maneira, ser o seu "proprietário".

\section{Inclusão financeira}

Um outro componente decisivo para o desenho dessa nova logística bancária está associado à crescente importância da inclusão financeira para as empresas do setor bancário. Segundo o Banco Central do Brasil (2011), um dos principais desafios da inclusão financeira é desenvolver canais de distribuição adequados que permitam que pessoas antes totalmente excluídas (ou pouco inseridas) dos sistemas financeiros formais tenham acesso a esses serviços e condição de decisão sobre seu uso para atendimento às suas necessidades. Dessa forma, "a utilização desses serviços financeiros deverá ser sustentável, garantindo o equilíbrio para a sociedade, para os agentes econômicos e, também, em nível individual, nas três dimensões do conceito de sustentabilidade: econômica, social e ambiental" (BANCO..., 2011, p. 17). Esse modelo de inclusão financeira é baseado no avanço das tecnologias que possibilitam a revisão da logística bancária.

De fato, a inclusão financeira passou a ser tema de interesse global e tornou-se um importante objeto de estudo, em razão de seu elevado benefício social e potencial econômico. Por isso, vem despertando a atenção de agentes econômicos que atuam em caráter local e global e disputam novos espaços numa arena competitiva cujos limites e modelos de negócio ainda não estão completamente definidos.

A inclusão financeira das pessoas menos favorecidas oferece um grande potencial de alavancagem para a economia das regiões nas quais esse segmento se concentra, trazendo esse público à economia formal. Além disso, é, de fato, plausível que, com as novas tecnologias, canais de distribuição bancária e novos modelos de negócios dentro do mercado financeiro, esse público venha a agregar rentabilidade às instituições financeiras, $\mathrm{o}$ que antes não acontecia, devido à inviabilidade econômica ou ao baixo (ou nulo) benefício marginal de se investir em infraestrutura para atender a essa camada da população. Todas essas mudanças no sistema bancário, portanto, são viabilizadas essencialmente pelos avanços tecnológicos.

A seguir, vamos apresentar uma análise da inclusão financeira tendo como base quatro principais grupos de fatores associados a ela: os mercadológicos, os comportamentais, os regulatórios e os tecnológicos.

\section{Fatores mercadológicos}

Uma das principais estratégias de inclusão financeira sendo desenvolvidas ao redor do mundo é o branchless banking, interpretada como a bancarização por meio de quaisquer dispositivos ou agentes que possam ofertar todos ou alguns dos serviços e produtos constantes do portfólio dos bancos tradicionais e que sejam, de alguma forma, diferentes do sistema de agências bancárias tradicionais. McKay e Pickens (2010), em pesquisa com instituições de branchless banking, identificaram que os seus serviços são, em média, 19\% mais baratos do que aqueles prestados por instituições financeiras, e, para alguns serviços - tais como poupanças de médio prazo - pode ser até 50\% inferior.

Pickens, Porteous e Rotman (2009) afirmam que o sucesso da inclusão financeira via branchless bancking vai depender do desenvolvimento das tecnologias e modelos de negócios por parte da iniciativa privada.

Outra estratégia de inclusão financeira está relacionada ao desenvolvimento das chamadas instituições de microfinanças (IMFs). Essas instituições, pela própria natureza dos serviços que prestam, apresentam custos de administração e operação bastante elevados, em comparação com os 
dos bancos, pois trabalham com micro-operações, com maior quantidade de transações do que um banco com clientes de renda mais alta. Essa situação coloca essas instituições na posição de cobrar altas taxas de juros de um público com baixo poder de barganha. Governos, investidores e sociedade argumentam que cobrar tarifas excessivas daqueles que não têm outro meio de financiamento seria um abuso de poder injustificado e também um limitador ao desenvolvimento do País.

É razoável acreditar que as ineficiências as quais as IMFs ainda apresentam, e que impactam suas práticas de tarifação, podem estar associadas ao fato de atuarem em um mercado com menos concorrência, ainda em crescimento, e em fase de aprimoramento de seus modelos de negócios. Com o desenvolvimento do setor e aumento da concorrência, no entanto, é possível imaginar que poderá haver não somente uma diminuição natural das taxas cobradas como também um aumento da eficiência das instituições, que, de fato, ajudará a reduzir seus custos (ROSENBERG, GONZALEZ, NARAIN, 2009).

Também, o poder de captação dessas instituições não é tão forte quanto o de bancos maiores, que conseguem taxas inferiores. Muitas IMFs ainda dependem de subsídios e doações, mas, com o desenvolvimento do mercado, essas instituições devem passar a operar com maior diversidade de fontes de financiamentos, tais como depósitos de clientes, emissão de títulos, capital próprio, entre outros.

Logo, as instituições que antes faziam gestão somente de uma carteira de ativos começam a se preocupar com a gestão de ativos e passivos, passando a se envolver, como todos os demais participantes do mercado financeiro, com a relação risco-retorno, que, principalmente após as crises recentes, são foco primordial de qualquer instituição financeira. Assim, as IMFs, em seu processo de aperfeiçoamento e profissionalização, devem também desenvolver eficiência para controlar não apenas os riscos de crédito dos tomadores da instituição mas também os demais riscos enfrentados por outros tipos de instituições financeiras, tais como insolvência, câmbio e descasamentos entre passivos e ativos (BROM, 2009).

\section{Fatores regulatórios}

$O$ aumento da diversidade de serviços oferecidos via branchless banking provoca um aumento proporcional também dos riscos associados ao negócio. Portanto, para poder ofertar todos os serviços disponibilizados por canais bancários tradicionais, esse canal fica sujeito a regulamentações similares. Serviços de natureza mais simples, como o caso de sucesso do mobile wallet do Quênia, possuem baixo risco (por serem pré-pagos) e exigem níveis mais baixos de regulamentação. Assim, quanto mais cresce o risco dos negócios, mais os governos devem evoluir sua legislação, de maneira a proteger o sistema como um todo.

Encontrar a medida certa em termos de regulamentação é um desafio (LYMAN, PICKENS, PORTEOUS, 2008). Assim como o excesso de regulamentação pode aumentar os custos de transação e inibir o surgimento das iniciativas de branchless banking - enfraquecendo seu propósito essencial de bancarização dos mais pobres
- sua ausência pode deixar o sistema sujeito a bolhas e crises. Se o branchless banking ainda é pouco difundido, apesar do seu menor custo, um dos motivos é o baixo estímulo a mudanças regulatórias que permitiriam o seu funcionamento. E esse estímulo a mudanças está diretamente associado ao perfil da regulação do sistema financeiro, que protege as necessidades sociais e provê incentivos à infraestrutura financeira.

O papel dos governos na prevenção de crimes financeiros, assim como na regulamentação também das microfinanças, é primordial. Se o avanço das tecnologias propicia o aumento dos chamados e-crimes financeiros, aqueles que fazem uso dos novos canais disponibilizados pela logística bancária, os governos devem estabelecer regulamentações que estimulem as instituições financeiras a fazer maior quantidade de verificações de dados, visando diminuir seu risco financeiro. Assim, as novas tecnologias, que possibilitam o desenvolvimento de ferramentas para melhorar a análise de crédito e segmentação de clientes, também permitem o cruzamento e conferência de enormes quantidades de informações para prevenir crimes financeiros (THE ECONOMIST, 2012, p. 12). E isso vale tanto para o sistema financeiro tradicional quanto para o universo das microfinanças.

Também deve ser preocupação dos governos estabelecer formas de incentivo aos projetos de inclusão financeira que estimulem o seu desenvolvimento, deixando de ser puramente assistencialista e propiciando o desenvolvimento sustentável do segmento. Para tanto, é especialmente importante haver incentivos no sentido 
de construção de infraestrutura, quando necessário, de maneira a estimular instituições financeiras a aceitar o risco de entrar em novos empreendimentos, visando resultados possivelmente positivos que podem vir da inclusão das pessoas mais pobres no sistema bancário.

\section{Fatores comportamentais}

Quando se fala em inclusão financeira, em geral, o foco são as famílias pobres, mas não as extremamente pobres. Pessoas e famílias que vivem em situação de miséria acabam apresentando tamanhas necessidades urgentes - tais como alimentação, saneamento básico, habitação, mínimo de infraestrutura - que as suas necessidades de inclusão financeira ficam em segundo plano. Nesse caso, é possível, até mesmo, que haja receio e sensação de insegurança em entrar no sistema financeiro formal, por falta de conhecimento e de confiança em um sistema no qual, muitas vezes, não há contato físico com o dinheiro. Nesse cenário, educação financeira é absolutamente indispensável.

Os hábitos e culturas das sociedades são fortes determinantes de seus hábitos de consumo de serviços financeiros. O microcrédito, por exemplo, expandiu-se no mundo muito mais fortemente do que as micropoupanças. Em geral, isso acontece porque é difícil elaborar um sistema de poupar quantias muito pequenas que torne o negócio lucrativo para o sistema financeiro (CGAP, 2010).

Kempson e Whyley (1999) identificam quatro necessidades principais relacionadas a produtos e serviços financeiros para o público carente. São elas:

- Gestão do fluxo de caixa diá- rio, para facilitar pagamentos e recebimentos;

- Segurança financeira de longo prazo, com aposentadorias e seguros de vida;

- Segurança financeira de médio prazo, contra perda de emprego e garantia de manutenção de padrão de vida mínimo aceitável, além de seguro de itens de bens de consumo doméstico;

- Aquisição de bens de consumo.

- Para atender a essas necessidades, os serviços prestados a esse público devem ser caracterizados por:

- Simplicidade e transparência, que permitam visualizar se o dinheiro está rendendo tanto quanto deveria, se estão sendo cobradas taxas justas pelos serviços adquiridos, ajudando a manter o controle rigoroso;

- Custo e valoração do dinheiro, com oferta de produtos mais específicos, ou "quebrados", adequando os custos a necessidades específicas;

- Marketing apropriado, para estimular as ofertas que permitam inclusão financeira gradativa de pessoas que não tinham qualquer relacionamento estabelecido até então;

- Flexibilidade para renegociar termos ou diminuir pagamentos a um mínimo, pois a condição financeira das pessoas de baixa renda é bastante variável e suas necessidades podem mudar rapidamente;

- Mecanismos de cobrança adequados ao ciclo de recebimento.

\section{Fatores tecnológicos}

A disseminação dos serviços de telecomunicações está viabilizando rapidamente novas perspectivas de logística de serviços financeiros, conforme já mencionado. Resumidamente, Bader (2011) destaca como fatores críticos de sucesso dessas novas tecnologias: (i) a sua facilidade de uso, enfatizando seu uso intuitivo; (ii) a segurança, inclusive a percepção de segurança dos clientes; (iii) a conveniência, que vai ao encontro da tendência de convergência; e, finalmente, (iv) a escalabilidade, pois essas novas tecnologias vão necessariamente atender grandes quantidades de clientes.

Com tela e botões pequenos, e excesso de menus, o celular pode não ser o canal financeiro preferido de clientes de alta renda, que têm acesso a outras formas mais convenientes para realizar essas operações. No entanto, para o público de baixa renda, distante das agências bancárias e com baixo acesso a serviços financeiros, as transações por telefonia móvel podem tornar-se bastante atrativas. É por isso que o celular tem sido considerado como uma solução para o problema da bancarização.

Para implementar serviços financeiros via telefonia móvel, as instituições financeiras precisam inicialmente negociar com as operadoras desses serviços (MAS e KUMAR, 2008), o que garante a eficiência e segurança dos canais financeiros móveis. Controle sobre aspectos-chave, tais como qualidade do sinal captado, concede poder de barganha às operadoras nas suas negociações com bancos e IMFs. Operadoras de telefonia, por possuírem rede de postos de venda de cartões pré-pagos (ou convênios), podem expandir suas operações nesses pontos para oferecer também serviços de saque, o que é atrativo para que clientes 
possam facilmente ter acesso físico a dinheiro.

Dado que se trata de um canal inovador para inclusão financeira, é necessária uma comunicação eficientemente com os clientes, para educá-los sobre a existência e funcionamento dos serviços financeiros móveis, explicando os sistemas de segurança com o objetivo de reforçar a confiança no seu uso. Essa divulgação pode ser feita por meio de parcerias entre agentes financeiros e operadoras, aproveitando o canal de comunicação e relacionamento que estas já têm com o público de baixa renda.

A tecnologia móvel permite aos bancos disponibilizar maior gama de serviços, ampliando o portfólio oferecido e a facilidade de comunicação com os clientes atuais, otimizando a retenção de clientes. Por outro lado, esse serviço aumenta a base total de potenciais clientes, de fato aumentando o mercado. Sem contar a redução dos custos logísticos e atendimento a necessidades de "imediatismo" da sociedade.

O maior problema enfrentado por esse tipo de tecnologia, nos países em desenvolvimento, é a infraestrutura necessária para garantir cobertura de sinal de telefonia móvel em algumas regiões. Essa infraestrutura tem alto custo de implantação e, a não ser que o retorno esperado se justifique, há pouco incentivo para fazer os investimentos devidos.

Além disso, não há certeza de que os clientes serão receptivos a essa nova modalidade de bancarização, o que aumenta a resistência aos investimentos. Por esse motivo, é necessário avaliar a participação governamental no processo de garantir infraestrutura de telefonia a todos os habitantes nos países que mais precisam da inclusão financeira.

\section{Inclusão financeira no Brasil}

O governo brasileiro tem incentivado a inclusão financeira tanto para reduzir as desigualdades sociais e acelerar o desenvolvimento econômico do País quanto para fortalecer o principal canal da transmissão de sua política monetária, que é o próprio sistema financeiro (Banco..., 2011, p. 15). De fato, nos últimos anos, temos observado a "redução gradual e continuada nos elevados níveis brasileiros de desigualdade. [...] Emergiu uma nova classe média, cada vez maior. O número total de pobres também caiu." (Fishlow, 2011, p. 276).

Há muito a ser feito, entretanto, pois 55 milhões de pessoas no Brasil ainda recebem seus rendimentos em dinheiro (BADER, 2011), por estarem fora do sistema financeiro formal. Se a internet não pode ser considerada como um canal que vá contribuir efetivamente para a inclusão financeira no País, devido a sua baixa penetração nas classes D e E, a grande base de cartões (de crédito, de débito e de loja) em uso representa um elemento estratégico para os bancos em busca do objetivo de bancarização.

Dados apresentados pela Febraban (2011) indicam um aumento generalizado nas quantidades de transações financeiras no Brasil, em particular, aquelas realizadas por meio dos canais eletrônicos, inclusive cartões. Enquanto isso, a quantidade de correspondentes não bancários, modelo de branchless banking no País, cresceu $126,2 \%$ entre 2006 e 2010, muito mais do que qualquer outra rede de atendimento (Banco... e FEBRABAN, 2011).

$\mathrm{Na}$ prática, isso significa que, no Brasil, todos os municípios contam com algum canal de distribuição bancária. Devido a essa expansão, houve também aumento significativo no número de cartões e contas no País. Se o número de contas-correntes ativas no País ainda é bastante inferior à população nacional, o número de cartões de débito já a supera. O número de cartões de crédito, apesar de estar aumentando, ainda apresenta amplo espaço para crescimento, principalmente quando comparado ao número de cartões de débito.

Outro bom indicador da melhoria da inclusão financeira no Brasil é o crescimento do número de pessoas (CPFs) com relacionamentos ativos nas instituições financeiras, no período de 2006 a 2010, que chegou a $26,6 \%$ (FEBRABAN, 2011). Apesar disso, o Brasil tem menos da metade de agências bancárias por habitante do que se observa em países desenvolvidos.

Em termos de microfinanças, o Brasil tem se tornado um destino bastante atrativo para receber investimentos voltados a esse tipo de empreendimento financeiro, devido ao bom momento econômico, com estabilidade política e grau de investimento. É importante observar que o fomento às microfinanças tem recebido crescente dos investimentos por parte de investidores institucionais. Por isso, os recursos destinados a esse setor precisam, além de cumprir um papel social, de retornos compatíveis com os riscos assumidos.

O Brasil tem ainda ótimos níveis de penetração de celulares, o que também se constitui em uma vantagem para a construção 
da nova logística bancária e para o desenvolvimento da inclusão financeira. No Brasil, a cobertura de tecnologia de telefonia móvel já é bastante desenvolvida por todo o território nacional e, portanto, quaisquer iniciativas que façam uso da base instalada de rede das operadoras de telefonia celular têm boas chances de obter sucesso.

\section{CONCLUSÃO}

Analisando as condições para o desenvolvimento de uma nova logística bancária, que leve em consideração a inclusão financeira da população de mais baixa renda, pode-se, então, sistematizar os principais fatores envolvidos na construção desse novo cenário no Brasil. O Quadro 1, abaixo. apresenta uma síntese desses fatores, organizados pelos seus aspectos mercadológicos, regulatórios, comportamentais e tecnológicos.

No novo paradigma de distribuição bancária, resultante do avanço tecnológico, desintermediação e desregulamentação financeira e das novas demandas dos clientes, a mudança no seu comportamento definirá a dinâmica de relacionamento cliente-banco nos próximos anos.

No ambiente dos bancos, a adequada combinação dos canais preferenciais de relacionamento remoto, representados pela internet, autoatendimento, call center e mobile banking e otimizados pelas dimensões de transação e relacio- namento, será o meio propulsor da convergência, suportada por uma plataforma multicanal que permita que o atendimento aos clientes culmine em uma experiência única de relacionamento integrado e completo, conjugando os fatores conveniência, facilidade de uso e segurança - sempre atendendo à tendência de convergência e mobilidade de prestação dos serviços em geral. Todas essas evoluções, conjuntamente, acabam por viabilizar um fluxo pré-identificado de clientes, que constitui hoje um valioso ativo das instituições financeiras, permitindo o uso eficaz das ferramentas de CRM, tornando-se um instrumento de vantagem competitiva.

Munidos de novas tecnologias, os novos modelos de negócios e

\section{Quadro 1 - Fatores críticos para o desenvolvimento de uma nova logística bancária no Brasil}

\begin{tabular}{|c|c|}
\hline Aspectos & Fatores críticos \\
\hline Mercadológicos & $\begin{array}{l}\text { Taxas acessíveis - captação a custos baixos. } \\
\text { Modelo de negócio compatível com características do público-alvo. } \\
\text { Profissionalizar e aumentar eficiência das instituições de microfinanças. } \\
\text { Gestão do risco de inadimplência desse novo público. }\end{array}$ \\
\hline Regulatórios & $\begin{array}{l}\text { Prevenção aos e-crimes e à lavagem de dinheiro. } \\
\text { Regulamentação do setor de microfinanças de acordo com as características do setor - não muito rígida, } \\
\text { para não aumentar demasiadamente o custo, nem muito branda, para não elevar o risco das microfinanças. }\end{array}$ \\
\hline Comportamentais & $\begin{array}{l}\text { Simplicidade e transparência dos produtos e serviços financeiros. } \\
\text { Custo do serviço prestado e valorização do dinheiro. } \\
\text { Marketing apropriado ao público - considerando seus interesses e localização. } \\
\text { Flexibilidade dos produtos e serviços oferecidos. } \\
\text { Mecanismos de cobrança adequados. } \\
\text { Convergência com os hábitos culturais da região. } \\
\text { Estar acompanhados de iniciativas de educação financeira dessa população. }\end{array}$ \\
\hline Tecnológicos & $\begin{array}{l}\text { Facilidade de utilização e manuseio intuitivo. } \\
\text { Segurança das informações. } \\
\text { Escalabilidade. } \\
\text { Convergência. } \\
\text { Mobilidade. } \\
\text { Dinamismo - acompanhar tendências. }\end{array}$ \\
\hline
\end{tabular}


paradigmas do sistema bancário vêm viabilizando a diminuição dos custos e aumento da oferta e capilaridade dos serviços bancários, propiciando um novo cenário inédito - em que a inclusão financeira se torna, de fato, possível. Para atingir também esse público tão peculiar e específico, ainda não plenamente compreendido, é preciso analisar os fatores envolvidos com base nas quatro grandes dimensões analisadas neste ensaio: mercadológica, regulatória, comportamental e tecnológica.

\section{REFERÊNCIAS}

BADER, M. Congresso de Meios Eletrônicos de Pagamentos, 6, 2011. Disponível em http://www.abecs.org.br/ site/arquivo/2459-A-MarcosBader.pdf.

BANCO CENTRAL DO BRASIL. Relatório de inclusão financeira, n. 2, 2011.

BROM, K. Asset and liability management for deposit-taking microfinance institutions. Washington: 2009.

CERNEV, A; DINIZ, E; JAYO, M. Emergência da quinta onda de inovação bancária. AMCIS 2009. Disponível em http://aisel.aisnet.org/cgi/ viewcontent . cgi? article $=1079 \&$ contex $\mathrm{t}=$ amcis 2009 .

CGAP. Access to finance for the poor. Annual Report 2010.

FEBRABAN. Bancarização e inclusão financeira no Brasil. 2011. Disponível em http://www.febraban.org.br/p5a _52gt34++5cv8_4466+ff145afbb52ffrt g33fe36455li5411pp+e/sitefebraban/ BANCARIZA\%C7\%C3O\%20-\%20III\%20 Congresso\%20Latino\%20Americano\%20de\%20bancariza $\%$ E7\%E3o\%20
e\%20Microfinan\%E7as\%20-\%20FELABAN\%20-\%20JUNHO\%202011\%20-\%20FINAL.pdf.

FISHLOW, A. O novo Brasil: as conquistas políticas, econômicas, sociais e nas relações internacionais. São Paulo: Saint Paul, 2011.

FONSECA, C. E. C; MEIRELlES, F; DINIZ, E. H. Tecnologia bancária no Brasil: uma história de conquistas, uma visão de futuro. São Paulo: FGV-RAE, 2010.

KEMPSON, E; WHYLEY, C. Kept out or opted out? Understanding and combating financial exclusion. UK: The Policy Press, 1999.

LYMAN, T. R; PICKENS, M; PORTEOUS, D. Regulating transformational branchless banking: mobile phones and other technology to increase access to finance. Washington: 2008.

MAS, I; KUMAR, K. Banking on mobiles: why, how, for whom? Washington: 2008 .

McKAY, C; PICKENS, M. Branchless banking 2010: who's served? At what price? What's next? Washington: CGAP, 2010.

PICKENS, M; PORTEOUS, D; ROTMAN, S. Scenarios for branchless banking in 2020. Focus Note 57 . Washington: 2009

ROSENBERG, R; GONZALEZ, A; NARAIN, S. Are microcredit interest rates excessive? Washington: 2009.

THE ECONOMIST. Special report: international banking. 2012. 